\section{Giardia duodenalis infection and anthropometric status in preschoolers in Salvador, Bahia State, Brazil}

\author{
Infecção por Giardia duodenalis e estado \\ antropométrico em pré-escolares de Salvador, \\ Bahia, Brasil
}

\author{
${ }_{1}^{1}$ Instituto de Saúde Coletiva, \\ Universidade Federal da \\ Bahia, Salvador, Brasil. \\ 2 Escola de Nutrição, \\ Universidade Federal da \\ Bahia, Salvador, Brasil. \\ ${ }^{3}$ Instituto Multidisciplinar \\ em Saúde, Universidade \\ Federal da Bahia, Vitória da \\ Conquista, Brasil. \\ Correspondence \\ S. M. A. Matos \\ Instituto de Saúde Coletiva, \\ Universidade Federal da \\ Bahia. \\ Rua Basílio da Gama s/n, \\ Salvador, $B A$ \\ 40110-040, Brasil. \\ sheilaalvim@hotmail.com
}

\begin{abstract}
The aim of this study was to estimate the association between Giardia duodenalis infection and anthropometric deficits, as measured by weight-for-age and height-for-age. This crosssectional study included 629 children from 12 to 48 months of age, selected from 30 geographic areas in the city of Salvador, Bahia State, Brazil. Poisson regression and linear regression were used for the multivariate statistical analyses. G. duodenalis was diagnosed in 13.5\% of the children. The children's breastfeeding duration and living conditions (garbage collection and paved streets or sidewalks) modified the effect of $\mathrm{G}$. duodenalis infection on anthropometric status. Among infected children, there were statistically significant associations between weight deficit and shorter breastfeeding $(P R=2.22 ; 95 \% C I$ : 1.56-3.14) and inadequate paving of streets and sidewalks ( $P R=2.00$; 95\%CI: 1.37-2.92), while height deficit was associated with deficient public garbage collection ( $P R=2.21$; 95\%CI: 1.312.51). In the linear regression, the association with the anthropometric indicators remained positive and statistically significant. The child's unhealthy living environment aggravated the negative effect of G. duodenalis infection on anthropometric status, and breastfeeding was a protective factor in the outcome.
\end{abstract}

Giardia; Anthropometry; Preschool Child

\author{
Sheila Maria Alvim Matos 1 \\ Ana Marlúcia Oliveira Assis ${ }^{2}$ \\ Matildes da Silva Prado 1 \\ Agostino Strina 1 \\ Lenaldo Azevedo dos Santos 1 \\ Sandra Rêgo de Jesus ${ }^{3}$ \\ Maurício Lima Barreto 1
}

\section{Introduction}

Malnutrition and intestinal parasites, especially Giardia duodenalis infection, are found simultaneously in underdeveloped regions, and the bidirectional relationship between these two events is well known 1. Most studies investigating the influence of intestinal parasites on malnutrition are limited to regions where the two are highly prevalent $2,3,4,5$. However, even where moderate and severe malnutrition has been declining, as in the area where this study was conducted $6, G$. duodenalis infection can be expected to exert a limiting impact on childhood growth 7 .

The negative impact of $G$. duodenalis infection on anthropometric status can be explained by jeopardized food intake due to anorexia and poor absorption of macro and micronutrients. The infection can thus have a worse impact on preschool-age children, in whom nutritional needs are higher due to the intense linear growth and weight gain in this phase of life 8,9 .

Although G. duodenalis infection does not pose a direct risk of death in childhood, its association with malnutrition and diarrhea makes it an important health problem, and it can contribute indirectly to increased mortality rates in childhood 10.

In the preschool population in developing countries, the incidence of G. duodenalis infection is higher than in industrialized countries 11 and is heavily influenced by the children's sur- 
rounding socioeconomic and sanitary conditions 4,12 . Thus, low-income populations living with precarious sanitation are the most affected. In this context, inappropriate disposal of excreta, insufficient drainage of surface water, and scarce or inadequate water supply favor the dispersal of pathogens in the environment, especially when added to nonexistent or inadequate personal and household hygiene. Precarious basic sanitation further aggravates the risk of infectious and parasitic diseases, thereby negatively influencing childhood nutritional status. Thus, malnutrition and intestinal parasitic infections coexist in poor regions with adverse economic conditions.

Considering the limited exploration of this association in studies focusing on urban areas permeated by overt social, economic, and environmental disparities, the current article proposes to verify the association between $G$. duodenalis infection and anthropometric status in preschoolers in Salvador, Bahia State, Brasil.

\section{Material and methods}

The study adopted a cross-sectional design to investigate the relationship between G. duodenalis infection and childhood anthropometric status, within the context of a broader study aimed at evaluating the Epidemiological Impact of the Environmental Sanitation Program in the All Saints Bay-Blue Bahia, in Salvador 13,14. As part of this evaluation project, in the year 1997 a group of 30 geographic (sentinel) areas were selected in the city, located in ten different sewage basins. These areas represented the diversity of sanitary and socioeconomic conditions in the city, and they were chosen from 1,765 census tracts in Salvador based on the 1991 population census and totaling approximately 20 thousand households. The census tracts were classified in three different levels according to sewage disposal standards and family income. This procedure has been described elsewhere 15 . In each of these areas, households were selected with children less than three years of age.

The current study included 629 children 48 months of age oryounger that presented complete information in the variables used here. The study excluded children with discrepant values for the anthropometric indicators, as recommended by the World Health Organization (WHO) 16, based on the margins set for mean Z-score. The sample thus excluded cases with Z-scores of $<-5.0$ and $>$ +3.0 for height-for-age (H/A),$<-5.0$ and $>+5.0$ for weight-for-age (W/A), and $<-4.0$ and $>+5.0$ for weight-for-height $(\mathrm{W} / \mathrm{H})$.
Mild malnutrition was defined as mean Zscores less than -1 SD Z-score. Due to the reduced prevalence of moderate/severe anthropometric deficits ( $<-2$ SD Z-score), it was decided to include mild malnutrition as a nutritional risk condition. The inclusion of mild malnutrition in the analyses was further justified by the intense discussion of the relevance of this form of malnutrition for childhood mortality 17,18,19,20.

Weight and height/length measurements were used to evaluate the children's anthropometric status. The evaluation was performed from June to September 1998 in strategic sites previously scheduled for each residential area. The children were weighed on portable microelectronic scales with a capacity of $150 \mathrm{~kg}$ and accurate to $100 \mathrm{~g}$ (model E-150/3P, Filizola Balanças Industriais, São Paulo, Brazil), ceded by the defunct National Institute of Food and Nutrition/ Ministry of Health (INAN). Children younger and older than 24 months, respectively, were measured with wooden infantometers and stadiometers (Leicester Height Measure, Seca, Hamburg, Germany). The instruments were calibrated periodically and were replaced with inelastic tape measures when necessary. All the measurements were taken in tandem, by properly trained nutritionists and nutrition students, allowing a variation of $100 \mathrm{~g}$ and $0.1 \mathrm{~cm}$, respectively, for weight and length/height, and the mean of the two was used as the final measurement ${ }^{21}$. The recommended standards 16 and technical criteria 21 were observed in all stages of the anthropometric evaluation. Age was recorded from the birth certificate or child's health card, and the difference was calculated between the measurement date and the child's date of birth.

The study used ANTHRO - Software for Calculating Pediatric Anthropometry (Centers for Disease Control and Prevention, Atlanta, USA), which uses the National Center for Health Statistics standard 22 as the reference for deriving Z-scores for $\mathrm{H} / \mathrm{A}, \mathrm{W} / \mathrm{A}$, and W/H.

The parasitological survey was conducted in parallel with the anthropometric evaluation, and a single stool sample was taken for each child. The child's parent or guardian received at home a specific stool-test recipient with a lid, labeled and numbered, and was oriented on how to collect the stool sample in this recipient or directly from the diaper into the recipient. Stool samples were collected the day after the recipients were distributed, and two attempts were made when the specimen was not available on the scheduled day. When this criterion was not met, the child was considered lost to the sample. After the stool sample was taken, the specimens were placed in cold stor- 
age, transported to the laboratory, and examined the same day. Helminth diagnosis and fecal egg count used the Kato-Katz method 23 and G. duodenalis cysts were identified using the spontaneous sedimentation method 24 . According to the number of eggs excreted in the feces, the intensity of Ascaris lumbricoides infection was classified as mild ( $<5,000$ eggs/g), moderate (5,000-50,000 eggs/g), or heavy $(\geq 50,000$ eggs/g) and Trichuris trichiura infection as mild ( $\leq 1,000$ eggs/g), moderate (1,000-10,000 eggs/g), or heavy ( $\geq 10,000$ eggs/g) 25 . The mean number of eggs per gram of feces was also calculated.

Demographic, socioeconomic, and environmental data were obtained with a semi-structured, pre-coded questionnaire. Information on behavior standards for household and personal hygiene was obtained from the child's parent or guardian, and the behavior in which the child was involved was observed and recorded after each visit. This pattern was based on 34 behaviors related to the child or parent/guardian, which were grouped into 16 negative and 18 positive behaviors and situations. The standardized sum of these behaviors allowed classifying the sample into groups with "positive", "intermediate", and "negative behavior". More detail on this classification can be found in Strina et al. 14 and Barreto et al. 26.

Prevalence of $G$. duodenalis infection was adopted as the measure of occurrence and compared between the exposure groups using prevalence ratio (PR) as the measure of association.

Since the study outcome is not a rare event, overestimation of the odds ratio may be observed as compared to the prevalence ratio. Therefore, rather than using logistic regression, multivariate Poisson regression models were defined with robust variance 27,28 , considering $G$. duodenalis infection as the principal exposure and the H/A and W/A indicators as dependent variables.

Effect modification was interpreted as change in the magnitude of the effect in the presence of a third variable 29,30 . Wald test was used to evaluate interaction between an exposure variable and potential effect-modifying co-variables. "Interaction variables" were defined as those in which the $\chi^{2}$ reached a p-value $<0.10$.

The statistical criterion adopted for recognizing a confounder was a shift of at least ten percentage points in the measurement of association caused by the variable as compared to that estimated in its absence 29,30. The backward progressive elimination procedure was used to perform these statistics.

Multicolinearity between the independent variables was evaluated by means of correlation coefficients, and the absence of this condition was identified when the correlation coefficient was less than 0.3531 .

Given the characteristics of the sample calculation for the original study (cluster-sampled), the existence of interdependence was assumed between the measurements generated for children from the same sentinel area. Thus, it was necessary to weight the statistical analysis to adjust the standard errors to the intra-group correlation. The "jackknife" estimation method was used for this purpose, comparing the sentinel areas by executing the command for each area omitted from an observation in turn (Stata Statistical Software, Stata Corp., College Station, USA).

In addition to the use of the multivariate Poisson regression model, the choice was made for an alternative analytical strategy meeting the model's premises, namely the use of a multiple linear regression model with a robust estimate of variance. The hierarchical approach was used for entering the variables in the blocks 32 , initially adopting a statistical significance of 0.20 to select possible variables to be included in the multivariate model and a significance of 0.10 to select the variables that would remain in the model. Variables related to the child's factors (level 2) were added to this model, and the new analysis was conducted, maintaining in the model the variables with significance of 0.10 . The final model for predicting anthropometric deficit consisted of the variables selected in each of the stages.

Epi Info, version 6.4 (Centers for Disease Control and Prevention, Atlanta, USA) was the statistical package adopted for data entry, and the analyses were performed using Stata, version 9.0.

The study was approved by the Institutional Review Board of the Institute of Collective Health, Federal University in Bahia. Results of the stool tests (both positive and negative) were returned to the children's parents. In case of positive test results, the children received the appropriate treatment. When necessary, nutritional orientation was provided to the child's parent or guardian.

\section{Results}

The study population consisted of 336 boys and 293 girls, totaling 629 children. Moderate/severe anthropometric deficit was rare in this population, but $20 \%$ or more of the children showed mild deficit. Information the children's living conditions showed that few households lacked running water, but that nearly half had inadequate sewage disposal. Although most homes had adequate flooring, in the peridomiciliary environ- 
ment more than $50 \%$ of the streets and sidewalks were unpaved. The mothers had low schooling, and the vast majority had breastfed their children for less than six months (Table 1).

The most frequently detected intestinal parasite in these preschoolers was A. lumbricoides (23.1\%), followed by T. trichiura (16.5\%) and G. duodenalis (13.5\%). Ancylostomids, Strongyloides stercorali, Hymenolepis nana, and Entamoeba histolítica/E. dispar were found in less than $1.5 \%$ of the children (data not shown). The vast majority of the infections were mild, and just $10.3 \%$ and $2.0 \%$ of the infected children excreted approximately $50 \%$ of the Ascaris and Trichuris eggs, respectively (Table 2 ).

Table 3 shows the mean Z-score for the anthropometric indicators and anthropometric deficit prevalence rates for the 629 preschoolers, according to infection, without controlling for confounders. Among the infected children, the mean Z-score for the anthropometric indicators was always lower than that observed in uninfected children, and this difference was statistically significant for H/A and W/A. Prevalence of W/A deficit $(42.3 \%)$ was significantly higher for children infected with G. duodenalis. No statistically

Table 1

Characteristics of study population according to selected variables. Salvador, Bahia State, Brazil, 1998.

\begin{tabular}{|c|c|c|}
\hline Study variables & $\mathbf{n}$ & $\%$ \\
\hline Mild linear growth deficit * & 131 & 20.8 \\
\hline Moderate/severe linear growth deficit ** & 38 & 6.0 \\
\hline Mild weight deficit * & 145 & 23.1 \\
\hline Moderate/severe weight deficit ** & 32 & 5.1 \\
\hline Male gender & 336 & 53.4 \\
\hline \multicolumn{3}{|l|}{ Child's age (months) } \\
\hline$\geq 24$ and $<36$ & 206 & 32.8 \\
\hline$\geq 36$ and $<48$ & 150 & 23.9 \\
\hline 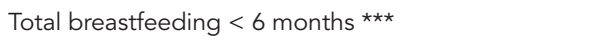 & 496 & 78.9 \\
\hline Mother with no schooling or incomplete elementary & 158 & 25.1 \\
\hline More than one child $<5$ years of age in household & 205 & 32.6 \\
\hline Negative hygiene habits & 79 & 12.6 \\
\hline Inadequate flooring & 36 & 5.7 \\
\hline Lack of running water & 80 & 12.7 \\
\hline Inadequate paving & 338 & 53.7 \\
\hline Inadequate sewage disposal & 294 & 46.7 \\
\hline Inadequate garbage collection & 173 & 27.5 \\
\hline
\end{tabular}

$\mathrm{N}=629$ children.

$\star \geq-2$ SD to $<-1$ SD Z-score;

$\star \star<-2$ SD Z-score;

$\star \star \star$ Median $=105.2$ days.
Table 2

Prevalence, intensity, and geometric mean egg count per gram of feces (epg) in children infected with A. lumbricoides and T. trichiura. Salvador, Bahia State, Brazil, 1998.

\begin{tabular}{lcc}
\hline Intestinal parasites & Children & $\%$ \\
\hline A. lumbricoides & 145 & 23.1 \\
Mild $(<5,000)$ & 548 & 87.1 \\
Moderate $(5,000-50,000)$ & 52 & 8.3 \\
Heavy (> 50,000) & 29 & 4.6 \\
Geometric mean epg (95\%Cl) & $7.293(5.4013-9.8469)$ \\
T. trichiura & 104 & 16.5 \\
Mild (<1,000) & 605 & 96.2 \\
Moderate (1,000-10,000) & 22 & 3.5 \\
Heavy (> 10,000) & 2 & 0.3 \\
Geometric mean epg (95\%Cl) & $2.577(2.164-3.070)$ \\
\hline
\end{tabular}

$\mathrm{N}=629$ children.

significant difference was observed between the prevalence rates for anthropometric deficit based on the $\mathrm{W} / \mathrm{H}$ indicator in infected versus uninfected children (Table 3).

Analysis of H/A showed interaction between frequency of public garbage collection and $G$. duodenalis infection $(\mathrm{p}=0.05)$. Using W/A as the outcome and $G$. duodenalis infection as the exposure variable, the variables total breastfeeding time ( $p=0.02)$ and paving of streets and sidewalks ( $p=0.10$ ) were confirmed as effect modifiers, indicating that the analyses needed to be stratified according to these variables.

The following variables were considered confounders: child's gender and age, number of under-five children in the household, frequency of public garbage collection, paving of streets and sidewalks, and presence of helminth infection.

After adjusting for socio-demographic and environmental variables, the association remained statistically significant between G. duodenalis infection and linear growth deficit $(\mathrm{PR}=$ 1.72; 95\%CI: 1.22-2.41) and weight deficit (PR = 1.81; 95\%CI: 1.31-2.51). When frequency of public garbage collection was inadequate, G. duodenalis infection was significantly associated with linear growth deficit (PR $=2.21$; 95\%CI: 1.32-3.69) (Table 4).

The results of the association between anthropometric deficit and G. duodenalis infection in preschoolers, stratified by the variables total breastfeeding time and paving of streets and sidewalks indicate that even after controlling for socio-demographic and environmental variables, positive and statistically significant associations remained for W/A deficit in the 
Mean Z-scores and standard deviations for anthropometric indicators and growth deficit prevalence rates in preschoolers according to intestinal parasite infection. Salvador, Bahia State, Brazil, 1998

\begin{tabular}{|c|c|c|c|c|c|c|}
\hline \multicolumn{7}{|c|}{ Anthropometric indicators } \\
\hline & \multicolumn{2}{|c|}{ Height/Age } & \multicolumn{2}{|c|}{ Weight/Age } & \multicolumn{2}{|c|}{ Weight/Height } \\
\hline & $n(\%)$ * & Z-score (SD) & $n(\%)$ * & Z-score (SD) & n (\%) * & Z-score (SD) \\
\hline \multicolumn{7}{|c|}{ G. duodenalis infection } \\
\hline Yes & $32(37.6)$ & $-0.771(1.056)$ & $36(42.3)$ & $-0.594(1.210)$ & $18(21.2)$ & $-0.106(1.133)$ \\
\hline No & $137(25.2)$ & $-0.340(1.085)$ & $141(25.9)$ & $-0.233(1.160)$ & $74(13.6)$ & $0.051(1.012)$ \\
\hline p-value & 0.016 & 0.001 & 0.002 & 0.008 & 0.066 & 0.192 \\
\hline \multicolumn{7}{|c|}{ A. lumbricoides infection } \\
\hline Yes & $50(34.5)$ & $-0.618(1.079)$ & $38(26.2)$ & $-0.374(1.169)$ & $15(10.3)$ & $0.067(1.012)$ \\
\hline No & $119(24.6)$ & $-0.332(1.086)$ & $139(28.7)$ & $-0.254(1.173)$ & 77 (15.9) & $0.019(1.035)$ \\
\hline$p$-value & 0.018 & 0.005 & 0.555 & 0.280 & 0.096 & 0.616 \\
\hline \multicolumn{7}{|c|}{ T. trichiura infection } \\
\hline Yes & $38(36.5)$ & $-0.697(1.116)$ & $35(33.6)$ & $-0.479(1.157)$ & $14(13.5)$ & $-0.001(1.012)$ \\
\hline No & $131(24.9)$ & $-0.339(1.076)$ & $142(27.0)$ & $-0.242(1.172)$ & 78 (14.9) & $0.036(1.034)$ \\
\hline$p$-value & 0.015 & 0.002 & 0.171 & 0.060 & 0.713 & 0.741 \\
\hline
\end{tabular}

$\mathrm{N}=629$ children; analysis not controlled.

* Children with anthropometric deficit $=$ Z-score $<-1 \mathrm{SD}$.

Table 4

Crude and adjusted associations between anthropometric deficits and G. duodenalis infection in preschoolers, according to interaction variables. Salvador, Bahia State, Brazil, 1998.

\begin{tabular}{|c|c|c|c|c|}
\hline $\begin{array}{l}\text { Interaction variables according to } \\
\text { anthropometric indicators }\end{array}$ & $\mathrm{PR}$ * & $95 \% \mathrm{Cl}$ & 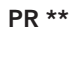 & $95 \% \mathrm{Cl}$ \\
\hline Height/Age (<-1 SD) & 1.49 & $1.10-2.04$ & 1.72 & $1.22-2.41$ \\
\hline \multicolumn{5}{|l|}{ Frequency of garbage collection } \\
\hline Adequate & 0.99 & $0.60-1.66$ & 1.41 & $0.84-2.37$ \\
\hline Inadequate & 2.16 & $1.42-3.28$ & 2.21 & $1.32-3.69$ \\
\hline Weight/Age (<-1 SD) & 1.63 & $1.23-2.17$ & 1.81 & $1.31-2.51$ \\
\hline \multicolumn{5}{|l|}{ Total breastfeeding (in months) } \\
\hline$\geq 6$ & 0.70 & $0.32-1.54$ & 0.98 & $0.40-2.39$ \\
\hline$<6$ & 2.06 & $1.51-2.81$ & 2.22 & $1.56-3.14$ \\
\hline \multicolumn{5}{|l|}{ Paving of street/sidewalk } \\
\hline Adequate & 1.01 & $0.55-1.88$ & 1.40 & $0.75-2.63$ \\
\hline Inadequate & 2.06 & $1.47-2.89$ & 2.00 & $1.37-2.92$ \\
\hline
\end{tabular}

* Crude prevalence ratio;

** Prevalence ratio adjusted for gender, age, number of children $<5$ years of age in household, paving of street/sidewalk, sewage disposal, frequency of garbage collection, and A. lumbricoides and T. trichiura infection.

presence of $G$. duodenalis infection, when the children were breastfed for less than six months $(\mathrm{PR}=2.22 ; 95 \% \mathrm{CI}: 1.56-3.14)$ and when they lived in households with inadequately paved streets and sidewalks (PR $=2.00$; 95\%CI: 1.37 2.92) (Table 4).
The results of the multiple linear regression analysis (data not shown), adjusted for maternal schooling, type of flooring, breastfeeding, and number of children in the household showed that G. duodenalis infection decreased the mean Z-score values for H/A and W/A by -0.318 (SE = 
$0.111 ; \mathrm{p}=0.008)$ and $-0.274(\mathrm{SE}=0.130 ; \mathrm{p}=0.045)$, respectively. This same analysis, focusing on $A$. lumbricoides and T. trichiura infection and adjusted for the same variables, showed that these infections did not significantly alter the mean $\mathrm{Z}$-score values for the two anthropometric indicators. The values observed for H/A were -0.010 ( $\mathrm{SE}=0.093 ; \mathrm{p}=0.914)$ for $A$. lumbricoides and -0.081 ( $\mathrm{SE}=0.109 ; \mathrm{p}=0.463$ ) for T. trichiura. Mean Z-score values for W/A showed a nonsignificant addition of $0.125(\mathrm{SE}=0.085 ; \mathrm{p}=$ 0.155 ) for $A$. lumbricoides and a non-significant decrease of $-0.024(\mathrm{SE}=0.147 ; \mathrm{p}=0.870)$ for $T$. trichiura.

\section{Discussion}

The results of this study highlight the relationship between childhood weight and height deficit and G. duodenalis infection, a common illness in underdeveloped countries marked by heavy social inequalities, like Brazil.

Among children infected with G. duodenalis, weight deficit was 1.8 times more frequent (95\%CI: 1.31-2.51) than in uninfected children. A longitudinal study in this same population by Prado et al. 7 showed a mean deficit of $0.4 \mathrm{~kg}$ in children infected with G. duodenalis.

In our study, when the analysis was stratified by the interaction variables total breastfeeding and paving of streets and sidewalks, this effect was modified, and the occurrence of anthropometric deficit increased, even when the association was adjusted for the other variables in the child's social, economic, and sanitary environment.

Based on this study's results, G. duodenalis infection is known to have contributed to weight deficit in the study population, independently of breastfeeding, although shorter breastfeeding potentiated the weight-for-age risk. The positive effect of breastfeeding on infant nutrition is well known, and the literature shows evidence of this effect, since G. duodenalis infection is more rare or milder (asymptomatic) in breastfed children 33,34 .

These results can be understood better in light of the lower exposure to contaminated foods and utensils when the child is breastfed, and especially due to the immune factors in maternal breast milk, involved in the protection against bacterial and parasitic infections (G. duodenalis infection, in the specific case of this study). The mechanism by which breast milk protects the child against these infections appears to be explained by the immune response promoted by secretory IgA in the intestinal tract, which mounts the local and systemic defense 35 , and the previously infected mother's antibodies 33 , which induce modulation of the response to future exposures and can exert a protective effect in the period after breastfeeding. The nonimmune components of maternal breast milk can also confer protection by destroying Giardia trophozoites in the intestinal lumen 33,34 . In this context, breastfeeding constitutes a protective factor for maintaining adequate anthropometric status, even in the presence of infection. It is thus possible to explain the potentiation of the negative effect of $G$. duodenalis infection on weight adequacy when breast milk is replaced totally or partially by other foods before the infant reaches six months of age.

A further result of exploring the interactions identified in this study was the association between $G$. duodenalis infection and weight deficit, which is twice as frequent (95\%CI: 1.37-2.92) when the child lives on an unpaved street. Meanwhile, irregular public garbage collection on the child's street was associated with an increase of 2.2 (95\%CI: 1.32-3.69) in linear growth deficit. Importantly, no independent association was observed between $G$. duodenalis infection and linear growth deficit; rather, this association was only seen when social and environmental factors were taken into account, modifying this relationship.

The evidence suggests that inadequately treated solid excreta represent a determinant factor for diseases. Accumulated garbage resulting from inadequate garbage collection and the presence of solid waste dumped at points close to residences favor the emergence of winged vectors that promote the spread of protozoa into households 36 . Curiously in the context of urban garbage in Salvador, especially in areas where this study was conducted - low-income suburban neighborhoods with precarious sanitation - we observed fecal contamination of domestic garbage (5\% of which consisted of disposable diapers and toilet paper) 37 , a condition that could readily facilitate the dispersion of Giardia by vectors 38 .

In these areas, urban and suburban clusters emerge with environmental and socio-demographic characteristics favorable to the spread of intestinal parasites, especially those transmitted by the fecal-oral route; both for school-age and preschool children, and various risk factors for this event have been identified 38,39.

In this sense, the associations observed in this study, even after controlling for socio-demographic and environmental variables, are probably explained by the high parasite burden of $G$. duodenalis infection. Experimental studies have 
demonstrated that the intensity of infection by this protozoan can be measured by the amount of cysts present in the feces, with great variation in animals 40 . Although quantification of Giardia cysts is not a commonly used technique in observational studies in humans, one can suppose that the parasite burden exerts some influence on anthropometric status in children who live in this unhealthy environment.

Although A. lumbricoides and T. trichiura were the most common of all the infections investigated in this study, they were not the ones that help explain the observed anthropometric deficits, as shown by the results of the multivariate linear regression. Still, these results do not suggest that helminth infections are harmless to childhood growth; rather they may indicate that in the presence of $G$. duodenalis infection in populations in which the mean helminth burden is low, the expected association, already observed in other studies 3,8,9, may have been inhibited, and the Giardia infection ends up having the greatest impact on nutritional status in preschoolers.

This study's results would certainly become even more important if malnutrition were classified based on a cutoff point of $<-2 \mathrm{SD}$, thus excluding the milder forms of the gradient. This approach was impossible, given the low rates of moderate and severe malnutrition, but the association was maintained nevertheless, analyzing the anthropometric indicators in their continuous form. From the perspective of epidemiology, these results become even more important by highlighting that $G$. duodenalis infection can at least partially explain mild anthropometric deficits, which still have a high impact on childhood growth patterns, even in the context of a decline in moderate and severe malnutrition, as observed recently in Brazil 41.

The results are subject to the inherent limitations of a cross-sectional design. This type of study limits the researchers' possibilities for inferring causal relations based on the observed associations. Another limitation, typical of any observational study, is the impossibility of controlling all the possible confounders, so that it becomes impossible to rule out residual confounding related to the principal association. On the other hand, our results corroborate similar findings in different contexts and with different methodologies, namely the effect of $G$. duodenalis infection on nutritional status 1,4,5,7.

In conclusion, in the population studied here, G. duodenalis infection was associated with childhood anthropometric deficit, an effect that proved more intense when associated with short breastfeeding and inadequate sanitation. Thus, measures to encourage breastfeeding and improvements in local sanitation should be adopted to reduce the occurrence of G. duodenalis infection. In contexts like the one studied here, in which severe forms of malnutrition are nearly non-existent, Giardia infection proves to be an important factor in maintaining mild forms of malnutrition. Although the clinical effects of the latter are scarcely visible for the children's immediate health and development, in the long term they are associated with a reduction in the odds of survival for these children 17,18,19,20. 


\section{Resumo}

Este estudo tem como objetivo estimar a associação entre a infecção por Giardia duodenalis e os déficits antropométricos segundo os indicadores peso por idade e altura/comprimento por idade. Trata-se de um estudo transversal envolvendo 629 crianças de 12 a 48 meses de idade, selecionadas em trinta áreas geográficas da cidade de Salvador, Bahia, Brasil. Adotou-se a regressão de Poisson e adicionalmente regressão linear nas análises estatísticas multivariadas. G. duodenalis foi diagnosticada em 13,5\% das crianças. O tempo de amamentação e as condições de residência das crianças (coleta de lixo e pavimentação da rua/calçada) modificaram o efeito da infecção por G. duodenalis sobre o estado antropométrico. Entre os infectados, observaram-se associações estatisticamente significantes do déficit ponderal com o menor tempo de amamentação (RP = 2,22; IC95\%: 1,56-3,14) e com as condições inadequadas de pavimentação da rua/calçada $(R P=$ 2,00; IC95\%: 1,37-2,92), e do déficit linear com a coleta pública de lixo ( $R P=2,21$; IC95\%: 1,31-2,51). Na análise da regressão linear, a associação se manteve positiva e estatisticamente significante com a média dos indicadores antropométricos. O ambiente insalubre em que vive a criança acentuou o efeito negativo da infecção por G. duodenalis sobre o estado antropométrico, e a amamentação ao peito constituiu-se em fator de proteção para este desfecho.

Giardia; Antropometria; Pré-Escolar

\section{References}

1. Gendrel D, Treluyer JM, Richard-Lenoble D. Parasitic diarrhea in normal and malnourished children. Fundam Clin Pharmacol 2003; 17:189-97.

2. Northrop-Clewes CA, Rousham EK, Mascie-Taylor CGN, Lunn PG. Anthelmintic treatment of rural Bangladeshi children: effect on host physiology, growth, and biochemical status. Am J Clin Nutr 2001; 73:53-60.

3. Hughes RG, Sharp DS, Hugues MC, Akau'ola S, Heinsbroek P, Velayudhan R, et al. Environmental influences on helminthiasis and nutritional status among Pacific schoolchildren. Int J Environ Health Res 2004, 14:163-77.

4. Carvalho-Costa FA, Gonçalvez AQ, Lassance SL, Silva Neto LM, Salmazo CAA, Bóia MN. Giardia lamblia and other intestinal parasitic infections and their relationships with nutritional status in children in Brazilian Amazon. Rev Inst Med Trop São Paulo 2007, 49:147-53.

5. Al-Mekhlafi MH, Azlin M, Nor Aini U, Shaik A, Sa'iah A, Fatmah MS, et al. Giardiasis as a predictor of childhood malnutrition in Orang Asli children in Malaysia. Trans R Soc Trop Med Hyg 2005; 99:686-91.

\section{Contributors}

S. M. A. Matos and A. M. O. Assis were the principal authors in charge of writing the paper. M. L. Barreto and A. M. O. Assis raised the funds and were the coordinators in charge of planning the study. M. S. Prado and M. L. Barreto planned the data collection design. A. Strina and M. S. Prado coordinated and S. M. A. Matos participated in the data collection. M. S. Prado supervised the laboratory analysis of the fecal samples. L. A. Santos, S. R. Jesus, and S. M. A. Matos performed the statistical analyses. All the authors contributed to the paper's revision and agreed with its submission.

\section{Acknowledgments}

This study received funding from the following institutions: Bahia State Secretariat for Urban Development (SEDUR), Brazilian National Research Council (CNPq), National Program for Excellence (PRONEX-CNPq), and Ministry of Health, through the Northeast Collaborating Center II (School of Nutrition, Federal University in Bahia).
6. Assis AMO, Barreto ML, organizadores. Condições de vida, saúde e nutrição na infância em Salvador. Brasília: Instituto Nacional de Alimentação e Nutrição/Salvador: Instituto de Saúde Coletiva, Universidade Federal da Bahia; 2000.

7. Prado MS, Cairncross S, Strina A, Barreto ML, Assis AMO, Rego S. Asymptomatic giardiasis and growth in young children; a longitudinal study in Salvador, Brazil. Parasitology 2005; 131:51-6.

8. Stephenson LS, Latham MC, Ottesen EA. Malnutrition and parasitic helminth infections. Parasitology 2000; 121:23-38.

9. Stephensen CB. Burden of infection on growth failure. J Nutr 1999; 129 Suppl 2:534-8.

10. Pelletier DL, Frongillo EA, Habicht JP. Epidemiologic evidence for a potentiating effect of malnutrition on child mortality. Am J Public Health 1993; 83:1130-3.

11. Thompson RCA, Reynoldson JA, Mendis AHW. Giardia and giardiasis. Adv Parasitol 1993; 12:71160.

12. Ferreira MU, Ferreira CS, Monteiro CA. Tendência secular das parasitoses intestinais na cidade de São Paulo. Rev Saúde Pública 2000; 34(6 Suppl):73-82. 
13. Barreto ML, Strina A, Prado MS, Costa MC, Teixeira MG, Martins-Junior DF, et al. Saneamento básico e saúde: Fundamentos científicos para avaliação do impacto epidemiológico do programa de saneamento ambiental da Baía de Todos os Santos (Bahia Azul). In: Heller L, Moraes LR, Monteiro TC, organizadores. Saneamento e saúde. Brasília: Organização Pan-Americana da Saúde/Organização Mundial da Saúde; 1997. p. 9-35.

14. Strina A, Cairncross S, Barreto ML, Larrea C, Prado MS. Childhood diarrhea and observed hygiene behavior in Salvador, Brazil. Am J Epidemiol 2003; 157:1032-8.

15. Teixeira MG, Barreto ML, Costa MCN, Strina A, Martins Jr. D, Prado M. Sentinel areas: a monitoring strategy in public health. Cad Saúde Pública 2002; 11:1189-95.

16. Organización Mundial de la Salud. Medición del cambio del estado nutricional. Geneva: Organización Mundial de la Salud; 1995.

17. Pelletier DL. The potentiating effects of malnutrition on child mortality: epidemiologic evidence and policy implications. Nutr Rev 1994; 52:409-15.

18. Pelletier DL. The relationship between child anthropometry and mortality in developing countries: implications for policy, programs and future research. J Nutr 1994; 124(1 Suppl):2047-81.

19. Pelletier DL, Frongillo Jr. EA, Schroeder DG, Habicht JP. The effects of malnutrition on child mortality in developing countries. Bull World Health Organ 1995; 73:443-8.

20. Assis AMO, Barreto ML, Magalhães LP, Oliveira VA, Prado MS, Gomes GSS, et al. Determinants of mild-to moderate malnutrition in preschoolers in an urban area of Northeastern Brazil: a hierarchical approach. Public Health Nutr. http://journals. cambridge.org/action/displayIssue iid $=717516$ (accessed on 05/Aug/2007).

21. Lohman TG, Roche AF, Martorell R. Anthropometric standardization reference manual. Champaign: Human Kinetics Books; 1988.

22. National Center for Health Statistics. Growth curves for children birth-18 years. Washington DC: Department of Health Education and Welfare; 1977. p. 78-1650. (Vital and Health Statistics Series, $11)$.

23. Katz N, Chaves A, Pellegrino J. A simple device for quantitative determination of Schistosoma mansoni eggs in faeces examined by the thick-smear technique. Rev Inst Med Trop São Paulo 1972; 14:394-400.

24. Neva FA, Brown HW. Basic clinical parasitology. $6^{\text {th }}$ Ed. Norwalk: Appleton \& Lange; 1994.

25. World Health Organization. Prevention and control of intestinal parasitic infections. Geneva: World Health Organization; 1987. (Technical Report Series, 749).

26. Barreto ML, organizador. Avaliação do impacto epidemiológico do programa de saneamento ambiental da Baía de Todos os Santos (Bahia Azul). Salvador: Instituto de Saúde Coletiva, Universidade Federal da Bahia; 2002.
27. Barros AJD, Hirakata VN. Alternatives for logistic regression in cross-sectional studies: an empirical comparison of models that directly estimate the prevalence ratio. BMC Med Res Methodol 2003; 3:1-13.

28. Zou G. A modified Poisson regression approach to prospective studies with binary data. Am J Epidemiol 2004; 159:702-6.

29. Kleinbaum D, Kupper L, Morgenstern H. Epidemiologic research. Belmont: Lifetime Learning Publications; 1982.

30. Rothman KJ, Greenland S. Modern epidemiology. Philadelphia: Lippincott-Raven Publications; 1998.

31. Colton T. Estadística en medicina. Barcelona: Editorial Masson/Little Brown and Co.; 1993.

32. Oliveira LPM, Barreto ML, Assis AMO, Braga-Junior ACR, Nunes MFFP, Oliveira NF, et al. Preditores do retardo de crescimento linear em pré-escolares: uma abordagem multinível. Cad Saúde Pública 2007; 23:601-13.

33. Carlier Y, Truyens C. Influence of maternal infection on offspring resistance towards parasites. Parasitol Today 1995; 11:94-9.

34. Mahmud MA, Chappell CL, Hossain MM, Huang DB, Habib M, Dupont HL. Impact of breast-feeding on Giardia lamblia infections in Bilbeis, Egypt. Am J Trop Med Hyg 2001; 65:57-260.

35. World Health Organization. Complementary feeding of children in development countries: a review of current scientific knowledge. Geneva: World Health Organization; 1998. (Technical Report WHO/NUT/98.1).

36. Chavasse DC, Shier RP, Murphy AO, Huttly SR, Cousens SN, Akhtaar T. Impact of fly control on childhood diarrhoea in Pakistan: community randomised trial. Lancet 1999; 353:22-5.

37. Empresa de Limpeza Urbana de Salvador. Caracterização dos resíduos sólidos domiciliares da cidade de Salvador. Salvador: Empresa de Limpeza Urbana de Salvador; 1999.

38. Prado MS, Strina A, Barreto ML, Assis AMO, Paz LM, Cairncross S. Risk factors for infection with Giardia duodenalis in pre-school children in the city of Salvador, Brazil. Epidemiol Infect 2003; 130:1-8.

39. Al-Shammari S, Khoja T, El-Khwasky F, Gad A. Intestinal parasitic diseases in Riyadh, Saudi Arabia: prevalence, sociodemographic and environmental associates. Trop Med Int Health 2001; 6:184-9.

40. Geurden T, Claerebout E, Vercruysse J, Berkvens D. Estimation of diagnostic test characteristics and prevalence of Giardia duodenalis in dairy calves in Belgium using a Bayesian approach. Int J Parasitol 2004; 34:1121-7.

41. Instituto Brasileiro de Geografia e Estatística. Pesquisa de orçamentos familiares - 2002-2003 (POF): estado antropométrico infantil. http://www.ibge. gov.br/home/estatistica/populacao/condicaodevida/pof/2003medidas/default.shtm (accessed on 22/Dec/2006).

Submitted on $08 / \mathrm{Jul} / 2007$

Final version resubmitted on 22/Oct/2007

Approved on 08/Nov/2007 